\title{
Widespread Occurrence of Non-Enzymatic Deamidations of Asparagine Residues in Yersinia pestis Proteins Resulting from Alkaline pH Membrane Extraction Conditions
}

\author{
Moo-Jin Suh, Hamid Alami, David J. Clark, Prashanth P. Parmar, Jeffrey M. Robinson, \\ Shih-Ting Huang, Robert D. Fleischmann, Scott N. Peterson and Rembert Pieper*
}

J. Craig Venter Institute, 9704 Medical Center Drive, Rockville, MD 20850, USA

\begin{abstract}
Extraction of crude membrane fractions with alkaline solutions, such as $100-200 \mathrm{mM} \mathrm{Na}_{2} \mathrm{CO}_{3}(\mathrm{pH} \sim 11$ ), is often used to solubilize peripheral membrane proteins. Integral membrane proteins are largely retained in membrane pellets. We applied this method to the fractionation of membrane proteins of the plague bacterium Yersinia pestis. Extensive horizontal spot trains were observed in 2-DE gels. The $\mathrm{p} I$ values of the most basic spots part of such protein spot trains usually matched the computationally predicted $\mathrm{p} I$ values. Regular patterns of decreasing spot $\mathrm{p} I$ values and in silico analysis with the software ProMoST suggested ' $n-1$ ' deamidations of asparagine (N) and/or glutamine (Q) side chains for ' $\mathrm{n}$ ' observed spots of a protein in a given spot train. MALDI-MS analysis confirmed the occurrence of deamidations, particularly in $\mathrm{N}$ side chains part of NG dipeptide motifs. In more than ten cases, tandem MS data for tryptic peptides provided strong evidence for deamidations, with $\mathrm{y}$ - and b-ion series increased by 1 Da following N-to-D substitutions. Horizontal spot trains in 2-DE gels were rare when alkaline extraction was omitted during membrane protein sample preparation. This study strongly supports the notion that exposure to alkaline $\mathrm{pH}$ solutions is a dominant cause of extensive $\mathrm{N}$ and $\mathrm{Q}$ side chain deamidations in proteins during sample preparation of membrane extracts. The modifications are of non-enzymatic nature and not physiologically relevant. Therefore, quantitative spot differences within spot trains in differential protein display experiments following the aforementioned sample preparation steps need to be interpreted cautiously.
\end{abstract}

Key Words: Alkaline membrane extraction, deamidation, membrane proteome, spot train, two-dimensional gel electrophoresis.

\section{INTRODUCTION}

Proteomic analysis of bacterial pathogens is useful to determine the expression of virulence factors and to characterize their dynamic changes under varying environmental conditions [1]. Membrane-associated proteins often play important roles in virulence and are implicated in the modulation of cell surface characteristics of bacterial pathogens in their host environments. In the $\mathrm{Gram}^{-}$bacterium Yersinia pestis, such proteins are the plasminogen activator (Pla) [2], the capsular F1 antigen [3], components of the type III secretion system [3] and the outer membrane (OM) protein Ail [4]. Membrane proteins tend to be less abundant and are less soluble in aqueous buffers than cytoplasmic and periplasmic proteins. Membrane proteins are typically enriched in pellet fractions of cell lysates and selectively extracted from membrane phospholipids $[5,6]$. To isolate proteins with different membrane association features, the crude membrane fraction is washed with high salt buffers (e.g. 2.5 M NaBr), followed by alkaline extraction (e.g. $180 \mathrm{mM} \mathrm{Na}_{2} \mathrm{CO}_{3}$, pH 11.3) and solubilization of the remaining membrane pellet with a denaturing buffer (e.g. $8 \mathrm{M}$ urea, $2 \mathrm{M}$ thiourea and $1 \%$ amidosulfobetaine-14). High salt buffers solubilize extrinsic and membrane-adsorbed proteins by weakening their electrostatic interactions [7]. Alkaline extraction generates open

*Address correspondence to this author at the J. Craig Venter Institute, 9704 Medical Center Drive, Rockville, MD 20850, USA; Tel: (301) 795-7605; Fax: (301) 838-9142; E-mail: rpieper@jcvi.org membrane sheets from sealed membrane vesicles, resulting in removal of the majority of membrane-attached proteins devoid of transmembrane domains (TMDs) [8-10]. Detergents have varying degrees of effectiveness to solubilize and separate TMD proteins from associated phospholipids.

Post-translational modifications (PTMs) are biologically important, often enzymatic events that alter the function or the susceptibility of a given protein to degradation. Even though PTMs are not as frequent and less complex in bacteria compared to eukaryotes, they are known to occur. This includes the removal of short $\mathrm{N}$-terminal signal peptides sequences from proteins destined for export, the removal of longer peptides from the $\mathrm{N}$ - or C-termini of enzyme precursors, e.g. peptidoglycan hydrolases [8], the removal of Cterminal fragments from cell wall-anchored proteins in $\mathrm{Gram}^{+}$bacteria [9], phosphorylation of $\mathrm{T}, \mathrm{S}$ or $\mathrm{Y}$ residues [10], methylation [11] and even protein glycosylation [12]. Such PTMs can result in significant shifts of $\mathrm{p} I$ and $\mathrm{M}_{\mathrm{r}}$ values giving rise to spot trains in 2-DE gels. Glycosylation [13], phosphorylation [14], carbamylation [15] and proteolytic truncation [16] are known causes for altered $\mathrm{p} I$ and $\mathrm{M}_{\mathrm{r}}$ values of proteins. Phosphorylation results in acidic $\mathrm{p} I$ shifts by 1 to $2 \mathrm{pH}$ units per phosphoryl group [17]. Most PTMs are relatively infrequent and occur in small ratios compared to the unmodified protein. Therefore, the display of spot trains in 2-DE gels suggests chemical protein modifications rather than true PTMs. Frequently reported chemical modifi- 
cations are acetylation, deacetylation, deamidation, oxidation and dephosphorylation of amino acid side chains as well as tryptophan decomposition [18-20].

Spot trains of bacterial proteins with acidic $\mathrm{p} I$ shifts in 2DE gels have been reported, e.g. for Escherichia coli [21]. Acidic $\mathrm{p} I$ shifts have been associated with side chain deamidation reactions in the amino acids asparagine $(\mathrm{N})$ and glutamine (Q) for human blood plasma proteins [22]. Deamidation reactions of $\mathrm{N}$-glycine $(\mathrm{NG})$ sequences were linked to sample preparation issues [23] and reported for bacterial and eukaryotic proteins $[24,25]$. A single deamidated $\mathrm{N}$ or $\mathrm{Q}$ residue should result in a net $\mathrm{M}_{\mathrm{r}}$ gain of $1 \mathrm{Da}$ for a protein (not detectable in 2-DE gels) and a $\mathrm{pH}$-dependent net charge gain detectable as an acidic $\mathrm{p} I$ shift. The net $\mathrm{M}_{\mathrm{r}}$ gain of $1 \mathrm{Da}$ can be determined in MS and MS/MS spectra of peptides resulting from the digestion of deamidated proteins. Here, we investigated the molecular causes of the appearance of $Y$. pestis membrane proteins as horizontal spot trains with acidic $\mathrm{p} I$ shifts in 2-DE gels.

\section{MATERIALS AND METHODS}

\section{Bacterial Strains and Culture Conditions}

The $Y$. pestis strain KIM6+ used in this study is an avirulent derivative of the fully virulent KIM strain, which was cured of the pCD1 plasmid but retained the chromosomal pgm locus and the plasmids pMT1 and pPCP1 [18]. Aliquots of bacterial colony stocks grown on tryptose blood agar and stored at $-80^{\circ} \mathrm{C}$ were used to grow $5-10 \mathrm{~mL}$ pre-cultures in PMH2 media containing $10 \mu \mathrm{M} \mathrm{FeCl}{ }_{3}$ for 8-15 hours, followed by dilution into $0.5-1 \mathrm{~L}$ of the same media. Overnight cell cultures at $26^{\circ} \mathrm{C}$ were grown to an $\mathrm{A}_{600}$ of ca. 1.9-2.5. Cell pellets were harvested by centrifugation at $8,000 \times g$ for 15 min at $4{ }^{\circ} \mathrm{C}$ and washed with a $c a$. 30 -fold volume of 33 $\mathrm{mM} \mathrm{K}_{2} \mathrm{HPO}_{4}(\mathrm{pH}$ 7.5) as previously described [19].

\section{Membrane Protein Extraction from Y.pestis Cells}

A lysozyme/EDTA spheroplasting method was used to generate spheroplasts [20]. Following cell lysis by sonication using 1 min on/off cycles (level 30, Branson sonifier), a mixed membrane pellet with inner and outer membranes (IM and OM, respectively) was separated from soluble cytoplasmic fractions by centrifugation at $108,000 \times \mathrm{g}$ for $60 \mathrm{~min}$ at $4^{\circ} \mathrm{C}$. The crude membrane fraction was resuspended and homogenized in $10 \mathrm{mM}$ Tris- $\mathrm{HCl}$ ( $\mathrm{pH} 7.8), 5 \mathrm{mM}$ EDTA, $0.2 \mathrm{mM}$ DTT, $10 \mu \mathrm{g} / \mathrm{ml}$ Leupeptin, $5 \mu \mathrm{g} / \mathrm{ml}$ Pepstatin, 10 $\mu \mathrm{g} / \mathrm{ml}$ TAME and $2 \mathrm{mM}$ PMSF (ca. $10 \mathrm{~mL} / \mathrm{g}$ pellet weight). Sodium bromide was added to a final concentration of 2.5 $\mathrm{M}$, the membrane homogenate was stirred for $1 \mathrm{~h}$ at $20^{\circ} \mathrm{C}$ and centrifuged at $51,000 \times \mathrm{g}$ for $60 \mathrm{~min}$ at $4^{\circ} \mathrm{C}$. Proteins residing in the high salt-extracted membrane (hs-MBR) fraction were concentrated using Ultrafree- 4 membrane filter devices $\left(\mathrm{M}_{\mathrm{r}}\right.$ cutoff of $\left.10 \mathrm{kDa}\right)$ to $c a .1-2 \mathrm{mg} / \mathrm{mL}$ and measured with the bicinchoninic acid reagent (Pierce Chemicals, Rockford, IL). The residual membrane pellet was re-homogenized in an ice-cold solution of $0.18 \mathrm{M} \mathrm{Na}_{2} \mathrm{CO}_{3}$ (pH 11.3), $50 \mathrm{mM}$ DTT, $1 \mathrm{mM} \mathrm{CaCl}_{2}, 1 \mathrm{mM} \mathrm{MgCl}$ and $1 \mathrm{mM} \mathrm{MnCl}$. The membrane suspension was stirred for $1 \mathrm{~h}$ at $4^{\circ} \mathrm{C}$, followed by centrifugation at $108,000 \times \mathrm{g}$ for $60 \mathrm{~min}$ at $4^{\circ} \mathrm{C}$. In a control experiment, the alkaline extraction step was substituted with a $2^{\text {nd }}$ high salt extraction step with $\mathrm{NaBr}$. Proteins solubilized with the $\mathrm{Na}_{2} \mathrm{CO}_{3}$ extraction step, called the high $\mathrm{pH}$-extracted membrane (hpH-MBR) fraction, were concentrated to $c a$. 1$2 \mathrm{mg} / \mathrm{mL}$ in Ultrafree-4 devices as mentioned above. The membrane pellets were frozen at $-80^{\circ} \mathrm{C}$. Prior to protein analysis in 2-DE gels, these pellets - obtained from both the high $\mathrm{pH}$ and the control high salt extraction steps - were solubilized with $8 \mathrm{M}$ urea, $2 \mathrm{M}$ thiourea, $1 \%$ (w/v) amidosulfobetaine-14, $2 \mathrm{mM}$ tributylphosphine and $0.5 \%$ Bio-Lyte $\mathrm{pH}$ 3-10 carrier ampholytes. Following incubation for 30 $\mathrm{min}$ at $20^{\circ} \mathrm{C}$ and centrifugation at $16,200 \times \mathrm{g}$ for $15 \mathrm{~min}$, the supernatants (usb-MBR fractions) were analyzed, while the residual pellets were discarded.

\section{Protein Separation and Differential Protein Spot Display in 2-DE Gels}

Protein samples with an amount of $c a .100 \mu \mathrm{g}$ were loaded onto $24 \mathrm{~cm}$ IPG strips (pH ranges of 4-7 and 3-10) and separated in $1^{\text {st }}$ gel strips and $2^{\text {nd }}$ dimension slab gels $(25$ $\times 19.5 \times 0.15 \mathrm{~cm}) .2-\mathrm{DE}$ gel separation conditions, the gel staining with Coomassie Brilliant Blue (CBB), gel imaging methods as well as spot matching and relative quantitation using the gel image analysis software Proteomweaver vs.4.0 (Bio-Rad, Hercules, CA) were previously described [24].

\section{Mass Spectrometry and Bioinformatic Protein Analysis}

Peptide digests were analyzed using MALDI-TOF/TOF mass spectrometry (4700 Proteomics Analyzer, Applied Biosystems, Framingham, MA) and LC-nESI-MS/MS mass spectrometry (LTQ, Thermo Fisher Scientific). Methods for spot cutting, protein digestion with trypsin and technical details for the MS analysis with the LTQ instrument were reported previously [24]. All MS spectra represented signal averaging of 1,000 laser shots and, for MS/MS spectra, 3,000 shots. In the MS/MS mode for MALDI analysis, the collision energy used to fragment peptides was $1 \mathrm{kV}$. A default calibration was applied using a six-component peptide standard spotted onto six edge or corner positions of the MALDI target plate. Data were searched against the latest release of the $Y$. pestis KIM strain subset of the NCBInr database, using the Mascot search engine vs.2.1 (Matrix Science, London, UK). Carbamidomethyl was invariably selected as a fixed modification and two missed tryptic cleavages were allowed, both for MALDI and LC-MS/MS. The MALDI mass range of data acquisition in the MS mode was $\mathrm{m} / \mathrm{z}$ 800-4000. Search parameters included mass error tolerances of $\pm 100 \mathrm{ppm}$ for peptide ions and $\pm 0.2 \mathrm{Da}$ for fragment ions. Protein identifications were generally accepted as significant when a Mascot protein score $>75$ and one or more peptide e-values $<0.1$ were obtained. To search for protein deamidations, the web-based software Findmod (http://au. expasy.org/tools/findmod/) was used. Manual inspection of mass spectra was carried out using the Data Explorer ${ }^{\circledR}$ software vs.4.8 (Applied Biosystems). For bioinformatic predictions of protein export signal sequences, the algorithm SignalP (www.cbs.dtu.dk/services) was used [25]. The 2-DE gel analysis software ProMoST [26] was used to determine $\mathrm{p} I$ values and the pattern of spot trains in silico (http://prometheus.brc.mcw.edu/promost).

\section{RESULTS AND DISCUSSION}

Proteins isolated in various subcellular fractions of the $Y$. pestis $\mathrm{KIM} 6+$ strain grown at $26^{\circ} \mathrm{C}$ were profiled using $2-\mathrm{DE}$ 
gels, and spots were identified by tryptic peptide-based analysis of proteins with MS. This included the periplasm and cell culture supernatants [19], the cytoplasm and three fractions extracted from membrane pellets (unpublished data). Extensive protein spot trains were observed in 2-DE gels of those two membrane fractions whose proteins were exposed to a $\mathrm{pH} 11.3$ during the extraction steps. Spot trains were far less prevalent in cytoplasmic, periplasmic and high salt-extracted membrane (hs-MBR) fractions which were not exposed to a highly alkaline $\mathrm{pH}$. This study focused on the analysis of these spot trains and the inherent protein modifications from the high $\mathrm{pH}$-extracted membrane (hpH-MBR) fraction and the urea/thiourea/amidosulfobetaine-14-solubilized membrane (usb-MBR) fraction. Proteins derived from the usb-MBR fraction were also exposed to the $\mathrm{pH}$ of 11.3, because the extraction step was performed subsequent to high $\mathrm{pH}$ membrane extraction with $\mathrm{Na}_{2} \mathrm{CO}_{3}$. After membrane extraction, proteins and peptides derived from them were not exposed to a $\mathrm{pH}$ higher than 8.8 - during sample preparation for 2-DE, the IPG and SDS-PAGE separation steps or protein digestion with trypsin. By omitting the high $\mathrm{pH}$ membrane extraction step with $\mathrm{Na}_{2} \mathrm{CO}_{3}$, a control usb-MBR fraction was isolated in which many of the same integral membrane proteins were identified as in the usb-MBR fraction. However, spot trains in the control usb-MBR fraction were far less prevalent than in the alkaline $\mathrm{pH}$-extracted usb-MBR fraction. This is evident when comparing the spot patterns of the gel images in Figs. (1A and B). While double spots with different $\mathrm{p} I \mathrm{~s}$ were observed in the control experiment (Fig. 1B), more than $75 \%$ of the total spot volume for a double spot was usually associated with the more basic spot.

Protein identification of all the spots displayed in the gels of the $\mathrm{hpH}-\mathrm{MBR}$ and usb-MBR fractions by MS revealed that many proteins partitioned into both fractions. This is illustrated with a few examples in Fig. (2) (AtpD, OmpA, Psn and LamB). Proteins were displayed as spot trains with nearly identical experimental $\mathrm{M}_{\mathrm{r}}$ and $\mathrm{pI}$ values. It suggests that differential extraction of protein isoforms in the two fractions is highly unlikely. This notion is further supported by the fact that the $\mathrm{p} I$ spot variants are nearly absent in the control usb-MBR fraction (Fig. 1B). It can be concluded that the exposure to a high $\mathrm{pH}$ caused the emergence of protein variants with different $\mathrm{p} I$ values, displayed as horizontal spot trains. For example, OmpA and Pla did not display spot trains in the control usb-MBR fraction (Fig. 1B), but in the usb-MBR fraction (Fig. 1A). Acidic shifts for OmpA (b-1, b2) and Pla (a-1, a-2) spots were observed with $\mathrm{p} I$ values at $\sim 5.5$ and $\sim 5.9$ (Fig. 1A). These shifts could be due to the addition of one and two negative charges, respectively. Slight sample-to-sample variations of spot numbers and spot intensities in a given spot train were observed and seemed to be related to reproducibility differences in fractionation experiments rather than a lack of gel-to-gel reproducibility. For example, OmpA displayed a three-spot train in Fig. (1A) and a four-spot train in Fig. (2). Differences in spot train appearance comparing distinct proteins were far greater. As shown in Fig. (2), the outer membrane receptor y0850 featured eight spots, while AtpD featured only two spots. This suggested seven and one negative charge additions, respectively. Proteins with higher $M_{r}$ values featured more extensive spot trains, suggesting a higher number of modifiable amino acid residues.
We assessed whether the protein environment in the membrane mattered regarding spot train formation. Fba, a cytoplasmic enzyme and possibly a contaminant in the usbMBR fraction, featured a double spot. AtpD, a peripheral IM subunit of the membrane-associated ATP synthase, featured a spot train. Both OmpA and Pla are integral $\beta$-barrel OM proteins and also featured spot trains. All proteins are visualized and denoted in the gels of Fig. (1). Apparently, neither the membrane association type of a protein nor its localization (IM or OM) play a role in the emergence of spot trains after exposure to an alkaline $\mathrm{pH}$. We focused on the spot train analysis of integral OM proteins and cannot confirm this notion with highly reproducible data and statistical significance. In summary, membrane protein extraction under alkaline $\mathrm{pH}$ conditions caused widespread protein modifications which were visualized as horizontal spot trains in 2-DE gels and, considering acidic spot shifts, related to quantifiable differences in protein acidification.

Horizontal spot trains for bacterial membrane proteins have been previously reported. Spot trains of membraneassociated proteins were profiled in 2-DE gels after extraction/wash steps with $\mathrm{Na}_{2} \mathrm{CO}_{3}$ at the $\mathrm{pH}$ of 11 in E. coli [27] and Pseudomonas aeruginosa [28]. Similar spot trains were also detected for proteins after extraction/wash steps with lauryl sarcosine at the $\mathrm{pH}$ of 7.5-7.8, in Helicobacter pylori [29] and Pasteurella multocida [30]. Two studies reported spot trains for membrane-associated proteins, following cell lysis at a $\mathrm{pH}$ of 7.5-8.0 without detergent or carbonate wash steps, in Borrelia burgdorferi [31] and E. coli [21]. Apparently, spot trains and the underlying chemical modifications in proteins can result from sample preparation processes at a neutral $\mathrm{pH}$. In the E. coli proteome analysis [21], it was suggested that deamidation of $\mathrm{N}$ and $\mathrm{Q}$ side chains of proteins is a major cause of 2-DE spot trains. Deamidated human blood plasma proteins have also been linked to the formation of extensive horizontal 2-DE spot trains. Using MS analysis, Sarioglu et al. [22] determined a link between N side chain deamidation of proteins and the addition of negative charges which, in turn, results in spot trains with increasingly acidic $\mathrm{p} I$ values. Considering these reports, it was of particular interest to examine $Y$. pestis protein spot trains in the context of $\mathrm{N}$ and/or $\mathrm{Q}$ deamidations.

Using the ProMoST software, in silico predictions of $\mathrm{N}$ deamidation reactions supported the notion that such events had occurred in the examined $Y$. pestis proteome. As shown in Fig. (3) for three integral OM proteins (HmsH, YaeT and $\mathrm{y} 3404)$, differences in the experimental $\mathrm{p} I$ values and computed $\mathrm{p} I$ values of $\mathrm{N}$-deamidated protein versions for a given spot train were in excellent agreement. In silico side chain phosphorylation of $\mathrm{S}, \mathrm{T}$ or $\mathrm{Y}$ residues in the proteins resulted in spot trains stretched out across a wider $\mathrm{pH}$ range (not shown here). Gel staining with the dye ProQ Diamond did not provide any evidence for phosphorylation in membraneassociated proteins (data not shown). In summary, the simulation of N/Q deamidations using the ProMoST software was in good agreement with our experimental data. The number of spots (n) in a train appeared to correspond to the number of deamidations per protein molecule (n-1). The more acidic a given protein spot and the higher the $\mathrm{M}_{\mathrm{r}}$ value of the protein, the smaller the $\mathrm{pH}$ distance to its nearest spot neighbor. 


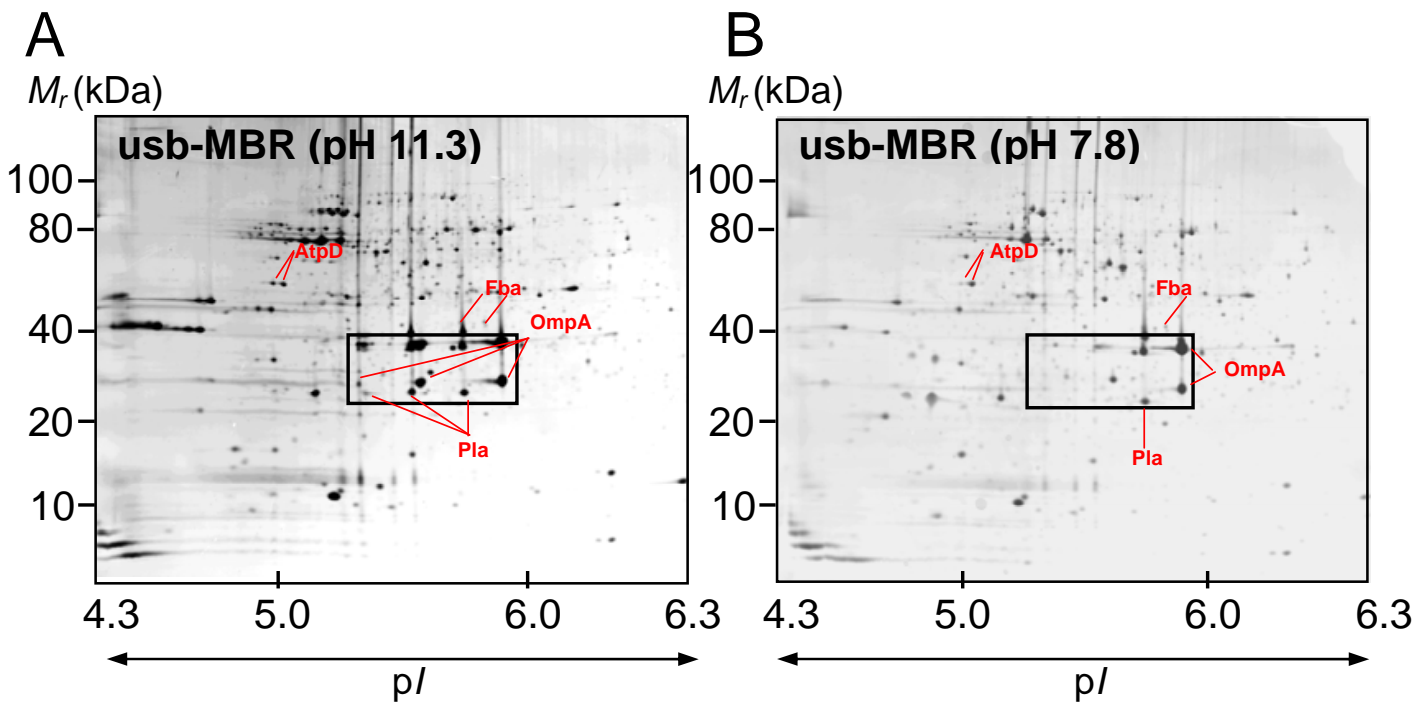

\section{C usb-MBR (pH 11.3)}

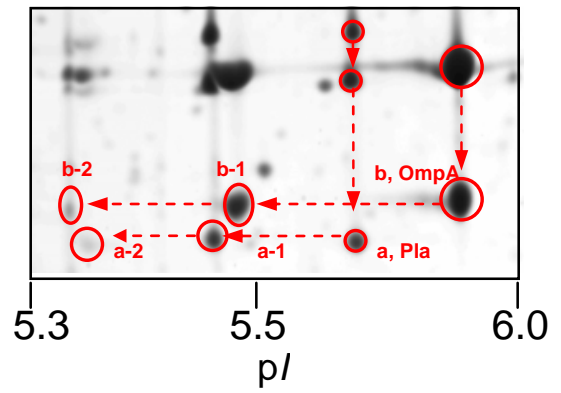

D usb-MBR (pH 7.8)

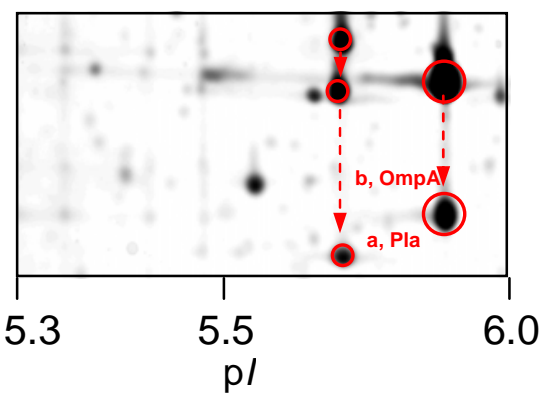

Fig. (1). Protein displays in 2-DE gels of $Y$. pestis KIM6+ membrane fractions isolated with (A,C) or without (B,D) extraction using an alkaline $\mathrm{Na}_{2} \mathrm{CO}_{3}$ solution. Circa $100 \mu \mathrm{g}$ protein was loaded onto an IPG strip ( $\left.24 \mathrm{~cm}, \mathrm{pH} 4-7\right)$, separated in the first dimension, followed by SDSPAGE (8-16\% T) in the second dimension. Gels were stained with Commassie Brilliant Blue G-250. pI and molecular mass ranges for the profiled proteins are denoted. Magnified gel segments of the denoted rectangles in $\mathbf{A}$ and $\mathbf{B}$ are presented in $\mathbf{C}$ and $\mathbf{D}$. The arrows indicate spots identified as OmpA and Pla. Vertical and horizontal spot trains for OmpA and Pla were reproduced in numerous 2-DE experiments.

To determine whether spot trains (multiple charge variants) indeed constituted deamidated proteins, more than 100 peptide mass fingerprint (PMF) and MS/MS datasets were examined. $\mathrm{N}$ side chain deamidation theoretically results in a mass shift of $+0.985 \mathrm{Da}$, and PMF data indeed revealed many such mass shifts in spots with acidic shifts on 2-DE gels. The detection of deamidations in high throughput MS analysis mode was difficult, however, because the mass change for a deamidated peptide is similar to that for a naturally occurring ${ }^{13} \mathrm{C}$ isotope. Nonetheless, an irregular isotopic peak height pattern with an apparent mass shift of +1 Da was indicative of deamidation. This is illustrated for three tryptic peptides (one for Pla and two for OmpA) in the MALDIMS spectra presented in Fig. (4). A tryptic peptide of Pla $\left({ }^{159}\right.$ FSWTATGGSYSYNN $_{172}$ GAYTGNFPK $\left._{181}\right)$ at $\boldsymbol{m} / \boldsymbol{z}, 2490.1$ was present as a monoisotopic peak in the most basic spot (spot a), but absent in spot a-1 (see also Fig. 1C). In contrast, the monoisotopic peak at $\boldsymbol{m} / \mathbf{z} 2491.1$, which was deamidated $\left(\mathrm{N}_{172} \rightarrow \mathrm{D}\right)$, was detected in spot a-1. The peptides of OmpA $\left({ }^{97}\right.$ GDINN $_{101}$ GAFK $_{105}$ and ${ }^{188}$ ETVGARPDN $_{196}$ GLLSVGVS$\left.\mathrm{YR}_{206}\right)$ at $\boldsymbol{m} / \mathbf{z} 935.5$ and 1990.0 , respectively, were present as monoisotopic peaks in the most basic spots (spots b), but weaker in spots b-1 and b-2 (Fig. 1C). The corresponding deamidated peptide peaks $\left(\mathrm{N}_{101} \rightarrow \mathrm{D}\right.$ and $\left.\mathrm{N}_{196} \rightarrow \mathrm{D}\right)$ at $\boldsymbol{m} / \boldsymbol{z}$ 936.5 and 1991.0, respectively, were stronger in spots b-1 and b-2 (Fig. 1C). Both of the deamidated peaks were observed in spot b-2. Lower peak heights of the unmodified peptide and the presence of more than one deamidated peptide in a given spot with one negative charge gain $(\mathrm{m} / \mathrm{z} 936.5$ and 1991.0, spot b-1) demonstrated that an individual protein spot was composed of a mixture of at least two distinct protein variants, each deamidated at a different $\mathrm{N}$ residue. Comparable results were reported in an analysis of human blood plasma proteins, but under experimental conditions without alkaline extraction [32].

Table 1 summarizes MS data for more than thirty peptides that featured isotope peak patterns with $+1 \mathrm{Da}$ mass shifts for monoisotopic peaks indicative of deamidation events. The list reveals that a $\mathrm{G}$ was frequently present $\mathrm{C}$ terminal to the deamidated $\mathrm{N}$ residue. For example, all three above-mentioned OmpA and Pla peptides harbored NG motifs. The proteins $\mathrm{PhoE}$ and y0850, displayed as multi-spot trains in Fig. (2), indeed harbored several NG motifs. MS 


\section{A Usb-MBR (pH 11.3)}

LamB, y0032

(pI 6.09, $M_{r}$ 53198)

AtpD, y4135

(pI 4.96, $M_{r}$ 50123)

OmpC, y2966

(pI 4.72, $M_{r}$ 38924)

RpoB, y0484

(pI 5.18, $\left.M_{r} 150390\right)$

Psn, y2404

(pI 5.38, $M_{r}$ 71473)

PhoE, y2983

(pI 5.15, $\left.M_{r} 38431\right)$

OmpA, y2735

(pI 5.88, $M_{r}$ 35873)

Put. mem. receptor, y0850

(pI 6.44, $M_{r}$ 80086)
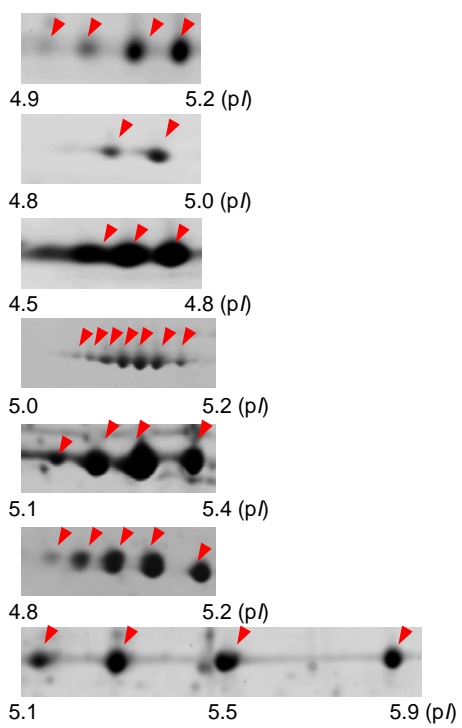

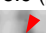

5.9

\section{B $\mathrm{hpH}-\mathrm{MBR}(\mathrm{pH}$ 11.3)}
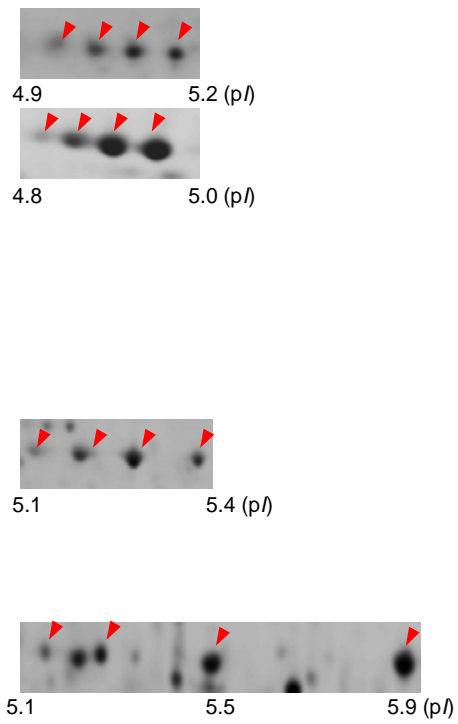

Fig. (2). Spot trains for proteins extracted in two membrane fractions. In hpH-MBR and usb-MBR fractions, membrane-associated proteins were exposed to an alkaline $\mathrm{pH}$ solution. Gel separation conditions were identical to those described in the legend of Fig. (1). For each of the gel segments, the arrows indicate spot positions with increasingly negative protein charges towards the acidic end of the gels. Protein names and gene loci are based on annotation data in the KIM genome. The calculation of $\mathrm{M}_{\mathrm{r}}$ and $\mathrm{p} I$ values included absent signal peptides of exported proteins, if applicable.
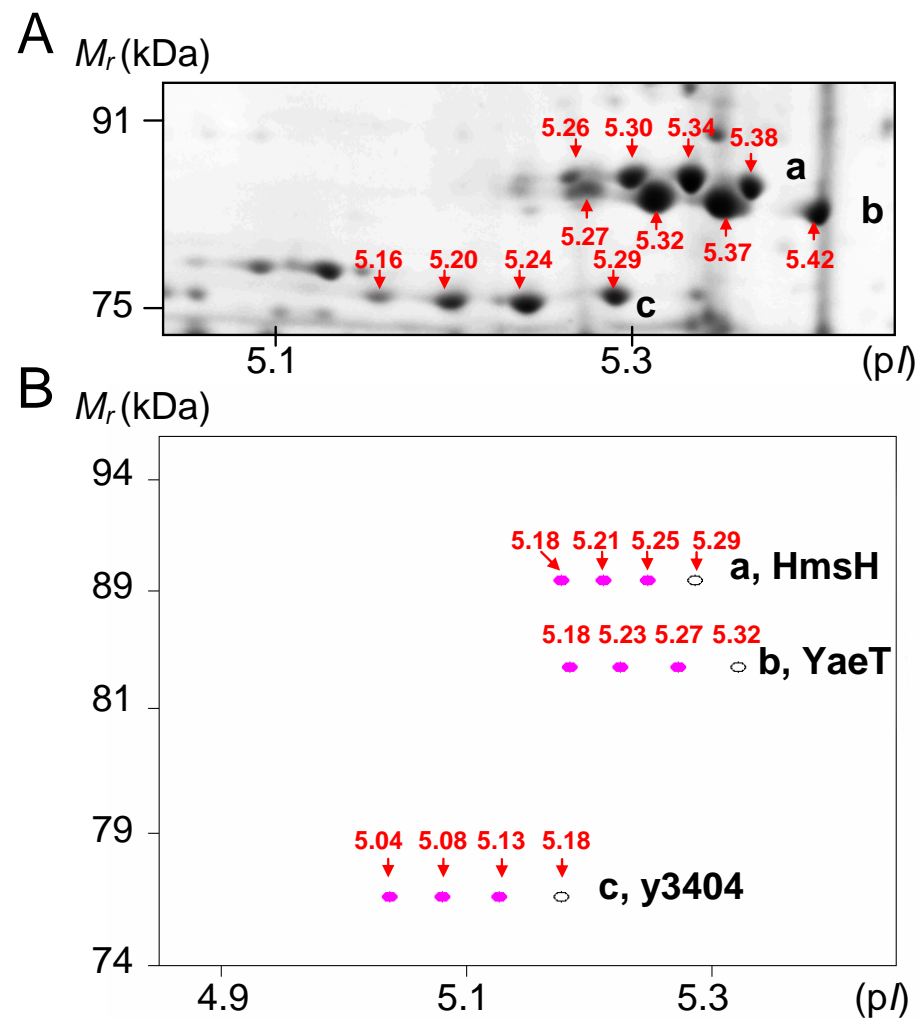

Fig. (3). Comparison of experimentally observed protein spot trains (A) and in silico predicted spot trains (ProMoST software) for equivalent proteins. Three in silico $\mathrm{N}$ deamidation events per protein were considered. The outer membrane proteins are HmsH (a), YaeT (b) and y3404 (c). Predicted spot patterns are similar to the experimental ones. The $\mathrm{p} I$ values denoted in $(\mathbf{B})$ are calculated for proteins devoid of signal peptide sequences. 


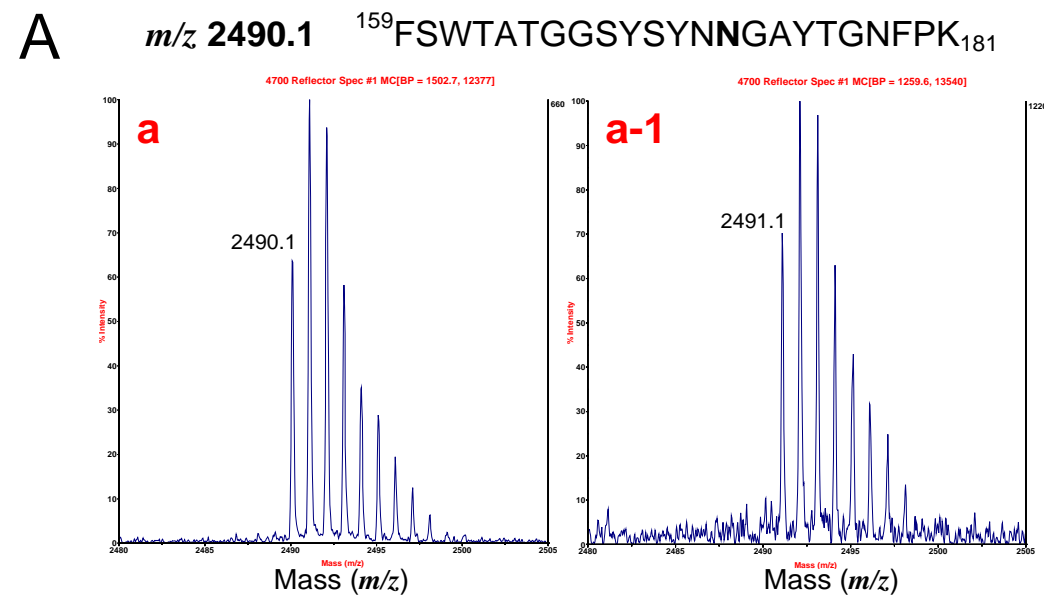

B $\quad \boldsymbol{m} / \mathbf{z} 1990.0{ }^{188}$ ETVGARPDNGLLSVGVSYR $_{206}$
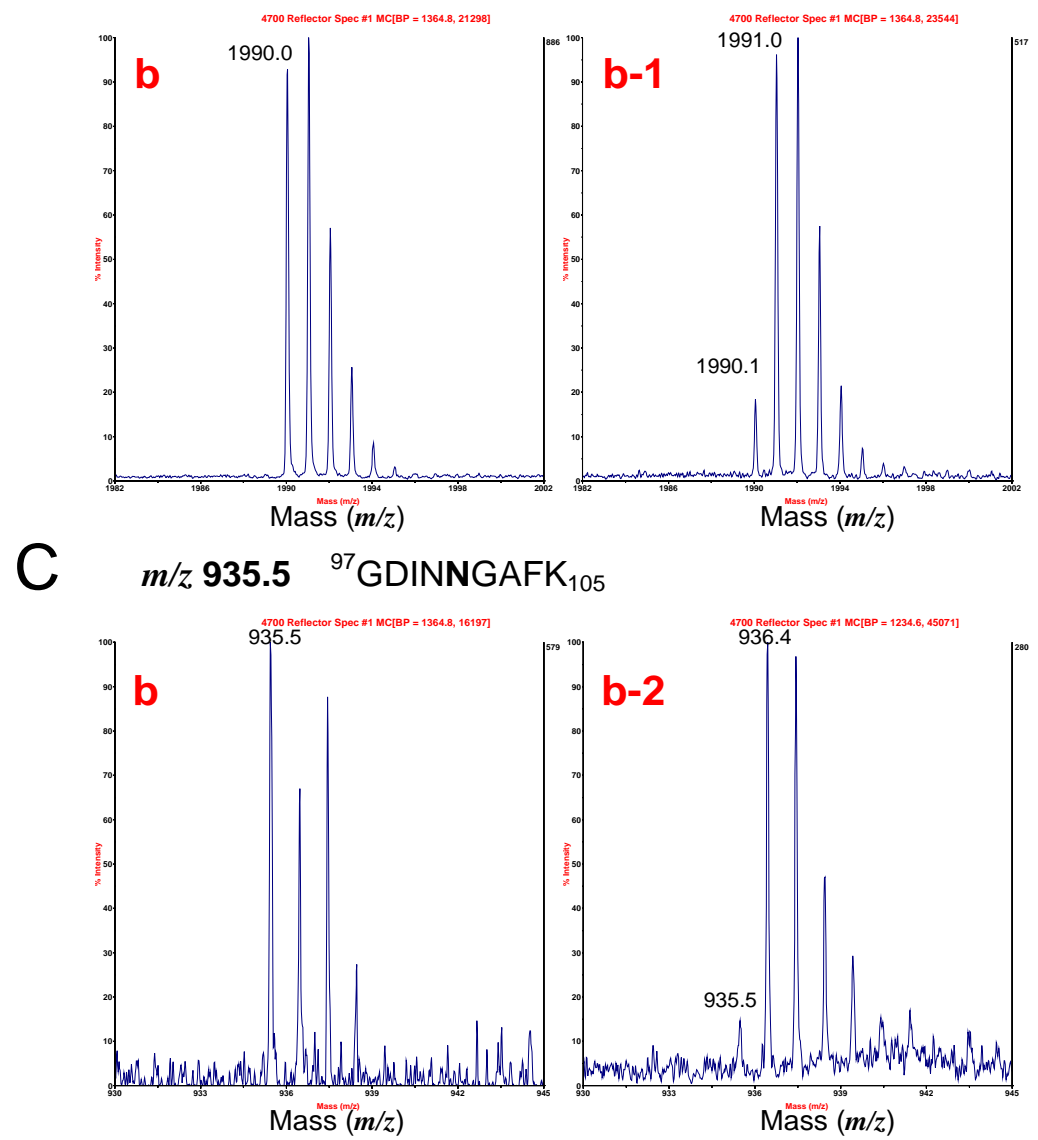

Fig. (4). MS spectra for N-deamidated peptides derived from the $Y$. pestis outer membrane proteins Pla and OmpA. The numbers denoted in the spectra (a, a-1, b, b-1, b-2) correspond to protein spots displayed in the 2-DE gel image of Fig. (1C).

data listed in Table 1 suggest that several proteins with acidshifted spots on 2-DE gels featured one or more peptides with +1 Da $m / z$ gains and NG motifs. Strong evidence for deamidations in NG motifs was obtained from the interpretation of MS/MS data. Fragment spectra for the unmodified OmpA peptide ${ }^{188}$ ETVGARPDN $_{196}$ GLLSVGVSYR $_{206}$ at $\boldsymbol{m} / z$ 1990.03 and the deamidated peptide ${ }^{188}$ ETVGARPDD $_{196} \mathrm{GL}-$ LSVGVSYR $_{206}$ at $\boldsymbol{m} / \boldsymbol{z}, 1991.02$ are provided in Fig. (5) and listed in Table 2 . b- and y- ions increased by 1 Da starting with $b_{9}$ and $y_{11}$ ions, respectively, were observed and result in assignment of the deamidation to residue $\mathrm{N}_{196}$. Evidence from MS/MS spectra for deamidation in NG motifs was obtained for 11 peptides, derived from 10 different proteins (Table 1). As expected, the peptides were invariably associated with acidic spot shifts. MS and MS/MS data also suggested deamidations in $\mathrm{Q}$ side chains, e.g. for the proteins YaeT, OmpF and Psn (Table 1). We conclude that both $Q$ and $\mathrm{N}$ side chains are susceptible to deamidation under alkaline conditions. MS data did not always allow conclusive evidence for the occurrence of $\mathrm{N}$ or $\mathrm{Q}$ deamidations, even if the associated spot trains were prominent and Mascot scores high. The addition of a negative charge occurring during 


\section{A $\quad \boldsymbol{m} / \mathbf{z} 1990.0{ }^{188}$ ETVGARPDNGLLSVGVSYR $_{208}$}
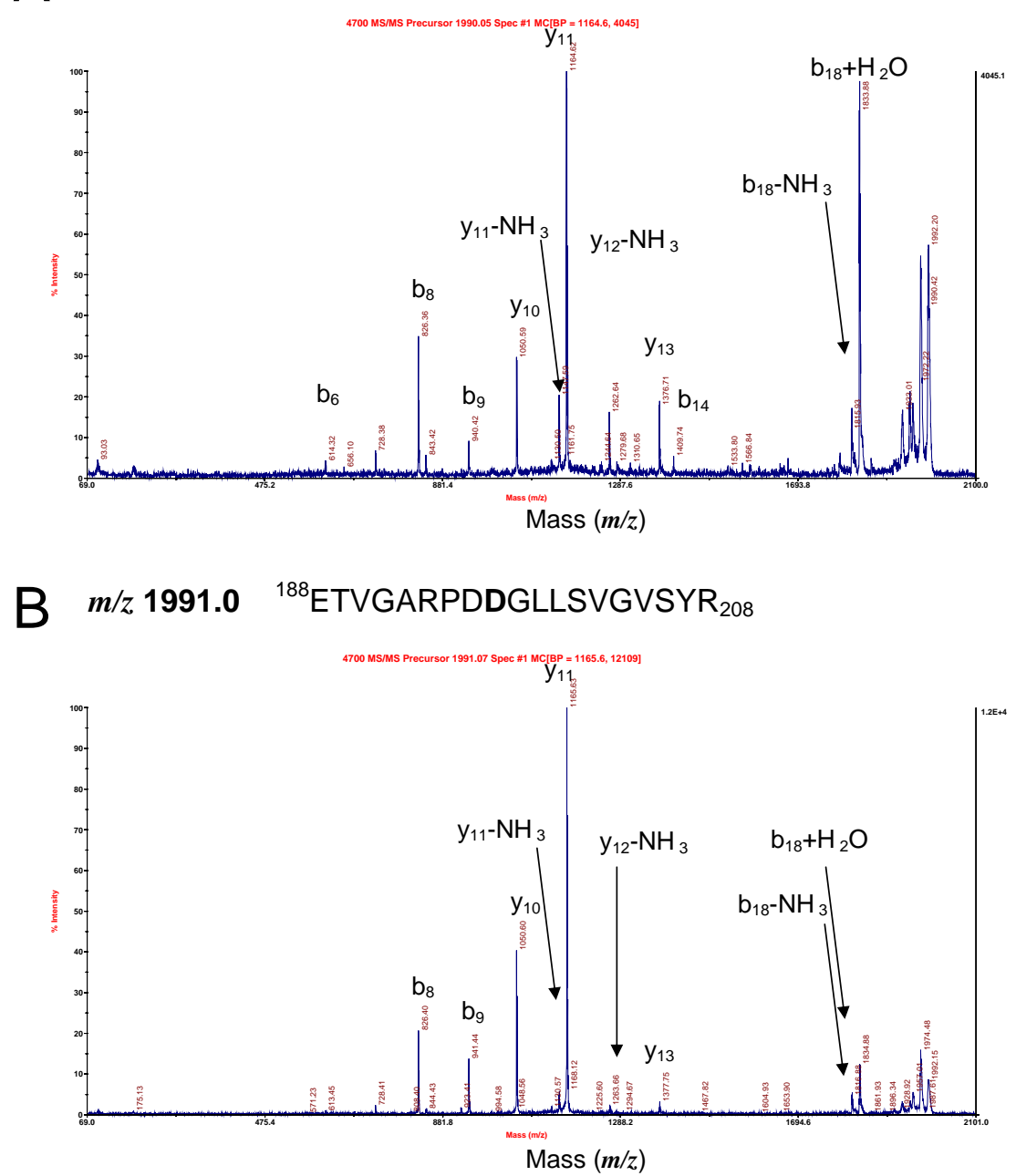

Fig. (5). Peptide fragment spectra for the unmodified tryptic peptide ${ }^{188}$ ETVGARPDN $_{196}$ GLLSVGVSYR $_{206}$ and the corresponding deamidated peptide of OmpA. The MALDI MS/MS spectra of the peptides with $m / z 1990.0$ and 1991.0 correspond to the peptide peaks displayed in Fig. (4B).

deamidation from $\mathrm{N}$ to $\mathrm{D}$ and $\mathrm{Q}$ to $\mathrm{E}$ can result in depression of the ionization efficiency in the positive ion mode of the MS analysis, thus making the validation of deamidations more difficult. Tryptic peptides with NG motifs and less than seven or more than 35 amino acids were often not detected in MS spectra. In summary, MS data provided strong evidence for deamidation events in numerous proteins with acidic spot shifts. We noticed a prevalence of $\mathrm{N}$ deamidations in proteins harboring NG motifs, indicative of the fact that a small residue $\mathrm{C}$-terminal to $\mathrm{N}$ facilitates deamidation. We have preliminary data supporting deamidations of $Y$. pestis proteins that were not exposed to alkaline solutions, in particular for proteins released from cells into extracellular media.

It was previously reported that deamidation proceeds more quickly, if $\mathrm{N}$ is followed by a small, flexible residue and exposed to alkaline environments [33, 34]. NG and NS sequences are particularly susceptible to deamidation [35]. A $70-80 \%$ ratio of $\mathrm{N}$ deamidation in $\mathrm{NG}$ motifs was reported by Krokhin et al. after prolonged tryptic protein digestion at a $\mathrm{pH}$ of 8.2 and at $37^{\circ} \mathrm{C}$ [23]. Here, we did not observe ex- tensive $\mathrm{N}$ deamidation resulting from in-gel tryptic protein digestion reactions. In the analysis of horizontal spots trains of human blood plasma proteins, deamidation was reported to contribute significantly to spot trains with a growing number of negative charges [22]. Several reports indicated that $\mathrm{N}$ or $\mathrm{Q}$ deamidation can be relevant in protein aging and degradation [36, 37], protein turnover [38], protein regulation [39] and apoptosis [40]. Deamidation in the context of protein aging would constitute a natural, though nonenzymatic process. Enzymatic post-translational deamidations have been discussed in the literature [41, 42], but there is general agreement that most deamidation events are nonenzymatic and influenced by physiological conditions during cell growth [36] and sample preparation [37]. $\mathrm{N}$ and $\mathrm{Q}$ residues in peptides and proteins were reported to be susceptible to deamidation not only at alkaline $\mathrm{pH}$ values, but also under certain ionic strength, temperature, protein-denaturating and solvation conditions [37].

There is currently no evidence for the biological significance of deamidations in membrane-associated proteins of $Y$. pestis or other Gram- bacterial pathogens. Extracellular, 
Table 1. Peptide Masses Indicative of $\mathbf{N}$ and Q Deamidations of Yersinia pestis Proteins

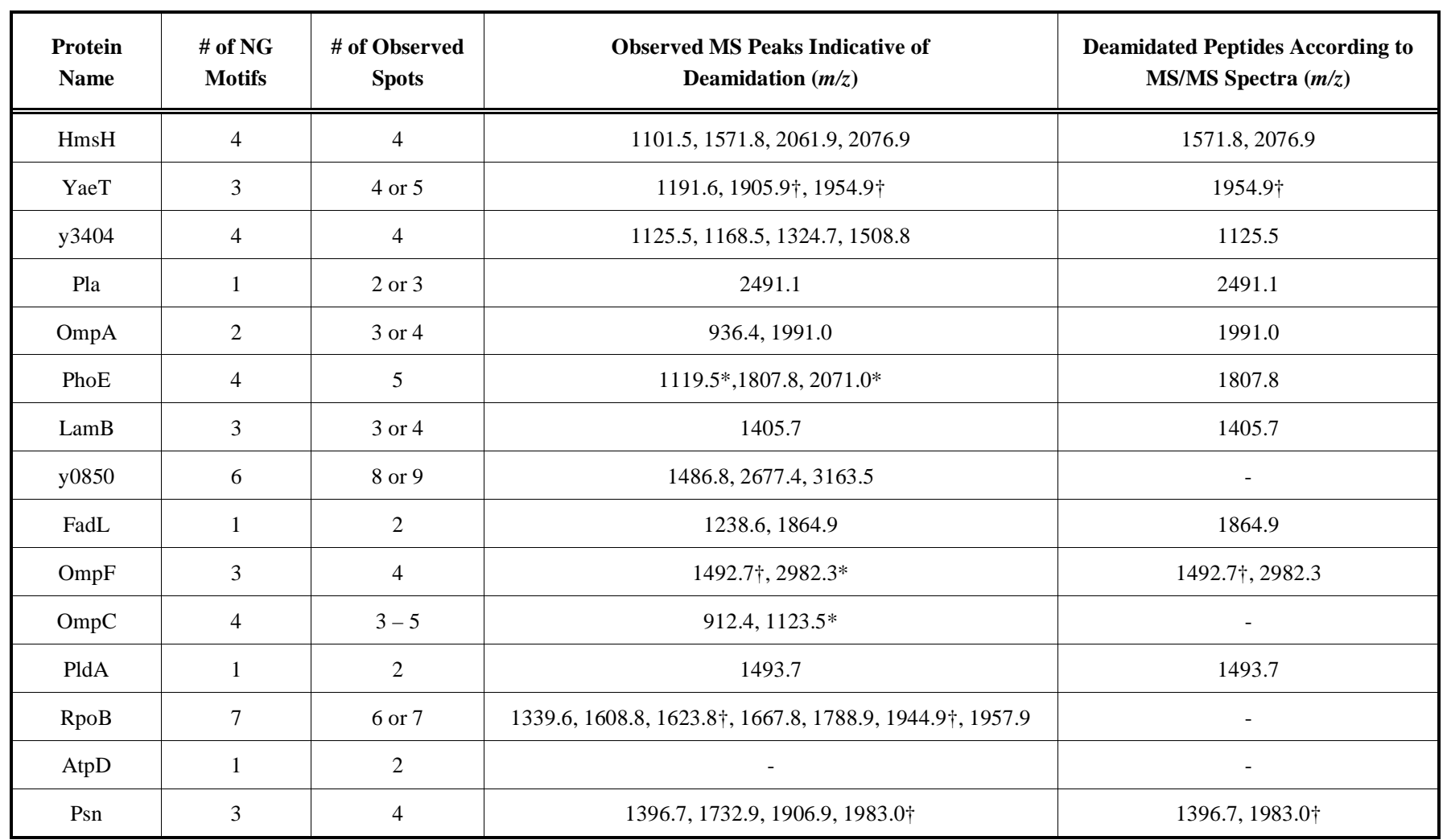

*Peptide contains two NG motifs; $\uparrow$ deamidation was observed for peptides with the amino acid Q; all N deamidations were related to NG motifs.

Table 2. Daughter Ions Produced by MALDI-MS/MS for a Deamidated Peptide of OmpA at $m / z, 1991.0$

\begin{tabular}{|c|c|c|c|c|}
\hline Observed $m / z$ & Calculated $m / z$ & $\Delta_{\text {obs-calc }}$ & Sequence & Ion Type \\
\hline 826.40 & 826.41 & -0.01 & ETVGARPD & $\mathrm{b}_{8}$ \\
\hline 941.44 & 940.45 & 0.99 & ETVGARPDN & $\mathrm{b}_{9}$ \\
\hline 1050.60 & 1050.60 & 0 & GLLSVGVSYR & $\mathrm{y}_{10}$ \\
\hline 1165.63 & 1164.64 & 0.99 & NGLLSVGVSYR & $\mathrm{y}_{11}$ \\
\hline 1263.66 & 1262.64 & 1.02 & DNGLLSVGVSYR-NH & $\mathrm{y}_{12}-\mathrm{NH}_{3}$ \\
\hline 1377.75 & 1376.72 & 1.03 & PDNGLLSVGVSYR & $y_{13}$ \\
\hline 1816.88 & 1815.92 & 0.96 & ETVGARPDNGLLSVGVSY & $b_{18}$ \\
\hline
\end{tabular}

outer membrane and periplasmic proteins are more exposed to environmental changes in $\mathrm{pH}$, temperature, oxidative and osmotic stress [43]. Interestingly, the four $\mathrm{N}$ side chains which are part of the NG motifs in the E. coli OM porin OmpG for which a crystal structure exists [44] are exposed on the periplasmic side, the cell surface and to the lumen of this porin. $\mathrm{N}$ deamidation of $\beta$-barrel porins could influence diffusion rates of small ions. Yersinia pestis expresses at least three porins $(\mathrm{OmpC}, \mathrm{OmpF}$, and $\mathrm{PhoE})$ all of which harbor NG motifs. All three proteins also formed marked spot trains under alkaline extraction conditions. Two $\beta$-barrel OM proteins (Pla and OmpA) not only displayed horizontal, 
but also vertical spot trains. In three repeated experiments, sequence coverage of the lower $\mathrm{M}_{\mathrm{r}}$ spots was identical to that of the higher $\mathrm{M}_{\mathrm{r}}$ spots, suggesting that incomplete unfolding accounted for the low $\mathrm{M}_{\mathrm{r}}$ spots. Incomplete unfolding in SDS-PAGE gels was previously observed for the orthologous E. coli protein OmpA [32]. It is known that OmpA migrates as a compact folded species unless it is completely heat-denatured [45]. Thus, such vertical spot trains are unrelated to amino acid modifications.

\section{CONCLUSION}

We demonstrated that $\mathrm{N}$ or $\mathrm{Q}$ side chain deamidation in membrane proteins exposed to highly basic $\mathrm{pH}$ solutions accounts for the formation of extensive spot trains in 2-DE gels. The evidence for non-enzymatic deamidation and a preference for deamidation in NG motifs is strong. It is plausible that deamidation of $Y$. pestis proteins exposed to the extracellular environment occurs naturally. This may contribute to protein aging, protein turnover and altered functions. Nonetheless, differential 2-DE display data with abundance changes in distinct spots of a protein spot train with characteristic acidic $\mathrm{p} I$ shifts are likely not physiologically important, particularly when proteins were exposed to alkaline solutions.

\section{ACKNOWLEDGEMENTS}

This work was performed under the Pathogen Functional Genomics Resource Center contract (contract No. N01AI15447), funded by the National Institute of Allergy and Infectious Diseases, National Institutes of Health. We thank Dr. Keehwan Kwon for helpful discussions.

\section{ABBREVIATIONS}

$\begin{array}{ll}\mathrm{IM} & =\text { Inner membrane } \\ \mathrm{OM} & =\text { Outer membrane } \\ \mathrm{TMD} & =\text { Transmembrane domain } \\ \text { hs-MBR } & =\text { High salt-extracted membrane } \\ \text { hpH-MBR } & =\text { High pH-extracted membrane } \\ \text { usb-MBR } & =\text { Urea/thiourea/amidosulfobetaine-14- } \\ & \text { extracted membrane }\end{array}$

\section{REFERENCES}

[1] Cash, P. Proteomics of bacterial pathogens. Adv. Biochem. Eng. Biotechnol., 2003, 83, 93-115.

[2] Kukkonen, M.; Suomalainen, M.; Kyllonen, P.; Lahteenmaki, K.; Lang, H.; Virkola, R.; Helander, I. M.; Holst, O.; Korhonen, T.K. Lack of O-antigen is essential for plasminogen activation by Yersinia pestis and Salmonella enterica. Mol. Microbiol., 2004, 51(1), 215-25.

[3] Cornelis, G. R. Yersinia type III secretion: send in the effectors. $J$. Cell. Biol., 2002, 158 (3), 401-8.

[4] Bartra, S.S.; Styer, K.L.; O'Bryant, D.M.; Milles, M.L.; Hinnebusch, B.J.; Aballay, A.; Plano, G.V. Resistance of Yersinia pestis to complement-dependent killing is mediated by the Ail outer membrane protein. Infect. Immun., 2008, 76, 612-622.

[5] Santoni, V.; Kieffer, S.; Desclaux, D.; Masson, F.; Rabilloud, T. Membrane proteomics: use of additive main effects with multiplicative interaction model to classify plasma membrane proteins according to their solubility and electrophoretic properties. Electrophoresis, 2000, 21, 3329-3344.

[6] Fischer, F.; Wolters, D.; Rogner, M.; Poetsch, A. Toward the complete membrane proteome: High coverage of integral membrane proteins through transmembrane peptide detection. Mol. Cell. Proteomics, 2006, 5,(3), 444-453.

[7] Schluesener, D.; Fischer, F.; Kruip, J.; Rogner, M.; Poetsch, A. Mapping the membrane proteome of Corynebacterium glutamicum. Proteomics, 2005, 5(5), 1317-30.

[8] Beukes, M.; Bierbaum, G.; Sahl, H.G.; Hastings, J.W. Purification of partial characterization of a murein hydrolase, millericin B, produced by Streptococcus milleri NMSCC061. Appl. Environ. Microbiol., 2000, 66, 23-28.

[9] Gaspar, A.H.; Marraffini, L.A.; Glass, E.M.; Debord, K.L.; TonThat, H.; Schneewind, O. Bacillus anthracis sortase A (SrtA) anchors LPXTG motif-containing surface proteins to the cell wall envelope. J. Bacteriol., 2005, 187, 4646-4655.

[10] Mougous, J.D.; Gifford, C.A.; Ramsdell, T.L.; Mekalanos, J.J., Threonine phosphorylation post-translationally regulates protein secretion in Pseudomonas aeruginosa. Nat. Cell. Biol., 2007, 9(7), 797-803.

[11] Paik, W.K.; Kim, S. Protein methylation. Science, 1971, 174, 114119.

[12] Benz, I.; Schmidt, M.A. Never say never again: protein glycosylation in pathogenic bacteria. Mol. Microbiol., 2002, 45(2), 267-76.

[13] Hsu, Y.R.; Hsu, E.W.J.; Katta, V.; Brankow, D.; Tseng, J.; Hu, S.; Morris, C.F.; Kenney, W.C.; Lu, H.S. Human keratinocyte growth factor recombinantly expressed in Chinese hamster ovary cells: Isolation of isoforms and characterization of post-translational modifications. Protein. Expr. Purif., 1998, 12(2), 189-200.

[14] Immler, D.; Gremm, D.; Kirsch, D.; Spengler, B.; Presek, P.; Meyer, H.E. Identification of phosphorylated proteins from thrombin-activated human platelets isolated by two-dimensional gel electrophoresis by electrospray ionization tandem mass spectrometry (ESI-MS/MS) and liquid chromatography electrospray ionization mass spectrometry (LC-ESI-MS). Electrophoresis, 1998, 19(6), 1015-1023.

[15] McCarthy, J.; Hopwood, F.; Oxley, D.; Laver, M.; Castagna, A.; Righetti, P.G.; Williams, K.; Herbert, B. Carbamylation of proteins in 2-D electrophoresis - Myth or reality? J. Proteome Res., 2003 2(3), 239-242.

[16] Phadke, N.D.; Molloy, M.P.; Steinhoff, S.A.; Ulintz, P.J.; Andrews, P.C.; Maddock, J. R. Analysis of the outer membrane proteome of Caulobacter crescentus by two-dimensional electrophoresis and mass spectrometry. Proteomics, 2001, 1(5), 705-720.

[17] Yamagata, A.; Kristensen, D.B.; Takeda, Y.; Miyamoto, Y.; Okada, K.; Inamatsu, M.; Yoshizato, K. Mapping of phosphorylated proteins on two-dimensional polyacrylamide gels using protein phosphatase. Proteomics, 2002, 2(9), 1267-1276.

[18] Fetherston, J.D.; Perry, R.D. The pigmentation locus of Yersinia pestis KIM6+ is flanked by an insertion sequence and includes the structural genes for pesticin sensitivity and HMWP2. Mol. Microbiol., 1994, 13(4), 697-708.

[19] Pieper, R.; Huang, S.T.; Clark, D.J.; Robinson, J.M.; Parmar, P.P.; Alami, H.; Bunai, C. L.; Perry, R.D.; Fleischmann, R.D.; Peterson, S.N. Characterizing the dynamic nature of the Yersinia pestis periplasmic proteome in response to nutrient exhaustion and temperature change. Proteomics, 2008, 8(7), 1442-58.

[20] Lucier, T.S.; Fetherston, J.D.; Brubaker, R.R.; Perry, R.D. Iron uptake and iron-repressible polypeptides in Yersinia pestis. Infect. Immun., 1996, 64(8), 3023-31.

[21] Lopez-Campistrous, A.; Semchuk, P.; Burke, L.; Palmer-Stone, T.; Brokx, S.J.; Broderick, G.; Bottorff, D.; Bolch, S.; Weiner, J.H.; Ellison, M.J., Localization, annotation, and comparison of the Escherichia coli K-12 proteome under two states of growth. Mol. Cell. Proteomics, 2005, 4(8), 1205-9.

[22] Sarioglu, H.; Lottspeich, F.; Walk, T.; Jung, G.; Eckerskorn, C. Deamidation as a widespread phenomenon in two-dimensional polyacrylamide gel electrophoresis of human blood plasma proteins. Electrophoresis, 2000, 21(11), 2209-2218.

[23] Krokhin, O.V.; Antonovici, M.; Ens, W.; Wilkins, J.A.; Standing, K.G. Deamidation of -Asn-Gly-sequences during sample preparation for proteomics: Consequences for MALDI and HPLC-MALDI analysis. Anal. Chem., 2006, 78(18), 6645-6650.

[24] Pieper, R.; Gatlin-Bunai, C.L.; Mongodin, E.F.; Parmar, P.P.; Huang, S.T.; Clark, D.J.; Fleischmann, R.D.; Gill, S.R.; Peterson, S.N., Comparative proteomic analysis of Staphylococcus aureus strains with differences in resistance to the cell wall-targeting antibiotic vancomycin. Proteomics, 2006, 6(15), 4246-4258. 
[25] Bendtsen, J.D.; Nielsen, H.; von Heijne, G.; Brunak, S. Improved prediction of signal peptides: SignalP 3.0. J. Mol. Biol., 2004, 340(4), 783-95.

[26] Halligan, B.D.; Ruotti, V.; Jin, W.; Laffoon, S.; Twigger, S. N.; Dratz, E. A. ProMoST (Protein Modification Screening Tool): a web-based tool for mapping protein modifications on twodimensional gels. Nucleic Acids Res., 2004, 32, W638-W644.

[27] Molloy, M.P.; Herbert, B.R.; Slade, M.B.; Rabilloud, T.; Nouwens, A.S.; Williams, K. L.; Gooley, A.A. Proteomic analysis of the Escherichia coli outer membrane. Eur. J. Biochem., 2000, 267(10), 2871-81.

[28] Nouwens, A.S.; Cordwell, S.J.; Larsen, M.R.; Molloy, M.P.; Gillings, M.; Willcox, M. D.; Walsh, B. J. Complementing genomics with proteomics: the membrane subproteome of Pseudomonas aeruginosa PAO1. Electrophoresis, 2000, 21(17), 3797-809.

[29] Baik, S.C.; Kim, K.M.; Song, S.M.; Kim, D.S.; Jun, J.S.; Lee, S.G.; Song, J.Y.; Park, J. U.; Kang, H.L.; Lee, W.K.; Cho, M.J.; Youn, H.S.; Ko, G.H.; Rhee, K.H. Proteomic analysis of the sarcosineinsoluble outer membrane fraction of Helicobacter pylori strain 26695. J. Bacteriol., 2004, 186(4), 949-55.

[30] Boyce, J.D.; Cullen, P.A.; Nguyen, V.; Wilkie, I.; Adler, B. Analysis of the Pasteurella multocida outer membrane sub-proteome and its response to the in vivo environment of the natural host. Proteomics, 2006, 6(3), 870-80.

[31] Nowalk, A.J.; Gilmore, R.D.Jr.; Carroll, J.A. Serologic proteome analysis of Borrelia burgdorferi membrane-associated proteins. Infect. Immun., 2006, 74(7), 3864-73.

[32] Ureta, A.R.; Endres, R.G.; Wingreen, N.S.; Silhavy, T.J. Kinetic analysis of the assembly of the outer membrane protein LamB in Escherichia coli mutants each lacking a secretion or targeting factor in a different cellular compartment. J. Bacteriol., 2007, 189(2), 446-454.

[33] Robinson, N.E.; Robinson, A.B. Prediction of protein deamidation rates from primary and three-dimensional structure. Proc. Natl. Acad. Sci. USA, 2001, 98(8), 4367-4372.

[34] Peters, B.; Trout, B.L. Asparagine deamidation: pH-dependent mechanism from density functional theory. Biochemistry, 2006, 45(16), 5384-5392.
[35] Steven, D.S. A modified peptide mapping strategy for quantifying site-specific deamidation by electrospray time-of-flight mass spectrometry. Rapid. Commun. Mass. Spectrom., 2007, 21(6), 830-836.

[36] Hochstrasser, D.F. Proteome in perspective. Clin. Chem. Lab Med., 1998, 36(11), 825-836.

[37] Wright, H.T. Nonenzymatic deamidation of asparaginyl and glutaminyl residues in proteins. Crit. Rev. Biochem. Mol. Biol., 1991, 26(1), 1-52.

[38] Gershon, H.; Gershon, D. Inactive enzyme molecules in aging mice: Liver aldolase. Proc. Natl. Acad. Sci. USA, 1973, 70(3), 909913.

[39] Reissner, K.J.; Aswad, D.W. Deamidation and isoaspartate formation in proteins: unwanted alterations or surreptitious signals? Cell. Mol. Life Sci., 2003, 60 (7), 1281-1295.

[40] Deverman, B. E.; Cook, B.L.; Manson, S.R.; Niederhoff, R.A.; Langer, E.M.; Rosova, I.; Kulans, L.A.; Fu, X.Y.; Weinberg, J.S.; Heinecke, J.W.; Roth, K.A.; Weintraub, S.J. Bcl-X-L deamidation is a critical switch in the regulation of the response to DNA damage. Cell, 2002, 111(1), 51-62.

[41] Yan, C.; Sloan, D.L. Purification and characterization of nicotinamide deamidase from yeast. J. Biol. Chem., 1987, 262(19), 90829087.

[42] Stewart, A.E.; Arfin, S.M.; Bradshaw, R.A. Protein NH2-terminal asparagine deamidase. Isolation and characterization of a new enzyme. J. Biol. Chem., 1994, 269(38), 23509-23517.

[43] Beveridge, T.J. Structures of gram-negative cell walls and their derived membrane vesicles. J. Bacteriol., 1999, 181(16), 4725-33.

[44] Koebnik, R.; Locher, K.P.; Van Gelder, P. Structure and function of bacterial outer membrane proteins: barrels in a nutshell. Mol. Microbiol., 2000, 37(2), 239-53.

[45] Freudl, R.; Schwarz, H.; Stierhof, Y.D.; Gamon, K.; Hindennach, I.; Henning, U. An outer membrane protein (OmpA) of Escherichia coli $\mathrm{K}-12$ undergoes a conformational change during export. $J$. Biol. Chem., 1986, 261(24), 11355-11361.

(C) Suh et al.; Licensee Bentham Open.

This is an open access article licensed under the terms of the Creative Commons Attribution Non-Commercial License (http://creativecommons.org/licenses/ by-nc/3.0/) which permits unrestricted, non-commercial use, distribution and reproduction in any medium, provided the work is properly cited. 